\title{
Rito y CEREMONIAL DE LA MUERTE EN LA COMARCA ONUBENSE \\ del Condado durante el Antiguo Regimen
}

http://dx.doi.org/10.33776/hh.v15i0.5284

\section{Rodolfo Manuel Clemente Martin \\ DOCTOR EN HISTORIA DEL ARTE \\ ro2manuel@yahoo.es}

Fecha de recepción: 28/01/2021

Fecha de aceptación: 10/02/2021

RESUMEN

Este artículo nos muestra los rituales funerarios y los espacios para los enterramientos en la comarca onubense del Condado durante el Antiguo Régimen o Edad Moderna

Palabras Clave

Ritos; funerales; enterramientos; cofradías; hermandades; cementerios; Condado; Bollullos, Almonte; Manzanilla.
Abstract

This article shows us the funeral rituals and burial spaces in the Huelva region of Condado during the Old Regime or Modern Age.

KEY WORDS

Rites; funerals; burials; brotherhoods; cemetery; Condado; Bollullos; Almonte; Manzanilla.

Un entierro, inhumación o exequias hacen referencia al conjunto de rituales y ceremonias que, tras el fallecimiento de una persona, acompañan al proceso de dar sepultura al cadáver. La naturaleza de los ritos funerarios -o de duelo- varía según la época, la cultura, la posición social del difunto y las creencias religiosas de la sociedad a la que pertenece el finado.

En el pensamiento colectivo de nuestros antepasados no había nada más irrefutable que la certeza de la muerte. En el Antiguo Régimen, el moribundo, todos sus familiares e incluso el pueblo eran conocedores del proceso de la muerte. La expiración acontecía en presencia de todos, era un acto solemne y público, en el que el moribundo era el protagonista. La muerte se convertía así en un espectáculo aleccionador, para todos aquellos que no acataban las leyes civiles o eclesiásticas.

El doliente, a veces cruelmente según se estima hoy día, era plenamente sabedor de su funesto destino, la agonía formaba parte del bien morir. A este punto parece referirse fray Luis de Granada del siguiente modo:

«...Tras desto llega el agonía de la muerte, que es la mayor de las batallas de la vida: cuando ya encienden la candela, y comienzan a aparejar el hábito o 
la mortaja, y dicen al doliente que es llegada la hora de la partida; que comience a encomendarse a Dios, y a llamar a su bendita Madre, que suele socorrer en aquella hora a los que llaman; cuando ya comienzan a sonar en las orejas del enfermo los gritos y gemidos de la pobre mujer, que comienza a sentir los daños de la nueva viudez y soledad; cuando ya comienza a despedirse el ánima de las carnes y al tiempo del despedirse cada uno de los miembros hace sentimiento por su salida» ${ }^{2}$.

\section{Muerte y PIEDAd A TRAVÉS DE LAS REgLAS DE LAS HERMANDADES}

«siento que me voy muriendoa toda prisa: tráiganme un confesor y un escribano, que en tales trances no se hade burlar el hombre con el alma» ${ }^{2}$.

En las reglas de las hermandades se recogen leyes y normas de comportamiento que son fiel reflejo de las pragmáticas emitidas por la Corona. Sin duda, a la hora de elaborar sus reglas, las hermandades, basaron muchos de sus capítulos en lo establecido en las Pragmáticas Reales y Constituciones Sinodales que sin duda, regulaban el día a día de la sociedad en lo civil y en lo religioso. En este sentido, cabe suponer que cuando se reúnen los miembros de la Hermandad de la Misericordia en la villa de Bollullos Par del Condado, para elaborar sus Reglas en 1579, debieron tener muy presentes no contravenir lo estipulado en la Pragmática de Felipe II emitidas en 1569. Asimismo, los acontecimientos calamitosos como la epidemia de la peste de landres y calenturas de 1568 debieron poner en alerta a las autoridades. Debido a ello, se redactaron varios informes y memorias sobre la epidemia que debían estar encaminados a servir de guía para un proyecto de organización sanitaria a nivel estatal.

Sobre el origen de la Hermandad de la Misericordia de Bollullos, la referencia más antigua que por el momento tenemos, es la que aparece en un inventario de propiedades de la Hermandad de 1754 , en el que hay una nota que dice:

«...este tributo lo reconoció a fabor de la Hermandad, Hernando Alonso por escriptura que otorgóen primero de octubre de mill quinientos y quarenta y cinco ante Alonso Domínguez, escribano de esta villa de Bollullos, de que hay copias entre los papeles de la hermandad....»

Por lo tanto, se ha de suponer que la Hermandad de la Misericordia ya existía para esa fecha de 1545 sin que por el momento podamos establecer una fecha precisa de su

1 FRAY LUIS DE GRANADA: De la oración y consideración. BAE, t. VIII. p. 39.

2 CERVANTES SAAVEDRA, Miguel de: Don Quijote de la Mancha. Capítulo LXXIV, PÁG. 346. Círculo de Lectores, 1987. Aquí Cervantes recuerda el libro de fray Felipe de Meneses titulado Luz del alma cristiana contra la ceguedad y la ignorancia. Valladolid, 1554. Y que Don Quijote vio en la imprenta barcelonesa, Capítulo LXII, pág. 306. 
fundación ${ }^{3}$. Tras el Concilio de Trento, la postura oficial de la Iglesia tiende hacia lo moderación en los duelos. Así, en 1575, Alonso de Orozco en su Victoria de muerte dedica su capítulo XXXI a la que la muerte se ha de llorar con moderación. Desde Trento, se postula que desde la Muerte y Resurrección de Cristo, se abren las puertas del cielo y por lo tanto, se puede acceder a la vida eterna, pues antes de Él, todos iban al limbo. Así pues, desde entonces, los llantos desproporcionados pierden toda justificación y era más valioso ayudar a los difuntos con piadosos sufragios agradables a los ojos de Dios para que tuviese a bien sacar al alma del difunto lo más pronto posible de su permanencia en el purgatorio ${ }^{4}$.

En las referidas Reglas de la Hermandad de la Misericordia de Bollullos, de 1579, se recoge que si algún hermano de la Hermandad se hubiese empobrecido, sea la Hermandad la que costease su enterramiento, y aún más, los hermanos estaban obligados a visitarlo y ayudarlo en su manutención y auxilio mientras durase su enfermedad. De este modo, los hermanos, bajo apercibimiento del muñidor, debían ir a visitar al enfermo de cuatro en cuatro. Además, al acercarse la hora de la muerte, se ordenaba que los clérigos que fueren hermanos de la Hermandad fuesen «allí a le visitar y consolar con sus oraciones y le lean los salmos de la penitencia con su letenía y oraciones.» ${ }^{5}$. Se muestra aquí, una vez más lo referido anteriormente, que la muerte era un acto público, todos sus familiares e incluso el pueblo eran conscientes y partícipes en el momento de la expiración.

El sacerdote se convertía en protagonista del suceso, era el único capaz de ayudar a que el alma del difunto alcanzase la salvación y por lo tanto desplazaba en protagonismo a la figura del galeno o matasanos, tan sólo aquellas personas que ayudaban al cuidado y atenciones del enfermo enfocado al bien morir, conseguían tener una cierta importancia en esos momentos. De tal forma, las visitas al enfermo por parte de los hermanos, establecidas en las reglas de la hermandad, suponían una de las costumbres más notables en los acontecimientos que se desarrollaban entorno a la expiración. El exceso de celo en la medida daba lugar a que a veces se creasen situaciones no deseables que en ocasiones se han recogido en algunos textos:

«son tantas las visitas que se alcançan unas a otras que de verdad si al enfermo lo tomasen sano con la importunación de tanto que tal estays: cómo os ha ydo la purga, cómo os sabe lo que comeys: de sano le tornarían enfermo...." ${ }^{6}$.

Asimismo, se consideraba que una dura y larga agonía era deseable para hacerse merecedor de alcanzar la vida eterna. Por ello, la presencia del sacerdote y hermanos para

3 A.G.A.S. Sec. II, Priorato de Ermitas, Leg. 1284.

4 OROZCO, Alonso de: Victoria de la muerte. Págs. 204-206.

5 Reglas de la Hermandad de la Misericordia de Bollullos Par del Condado. Realizada en la villa de Bollullos siendo hermano mayor de la Hermandad, Juan Barrera Pérez, y Alonso Miguel y Alonso Benites diputados...6 de enero de 1579. Archivo Histórico Nacional. Consejos, 31308. Exp. 1.

6 VENEGAS DEL BUSTO, Alejo.: Agonía del tránsito de la muerte con los avisos y consuelos que cerca d'lla son provechosos, Toledo, 1537. Pág. 26 
ayudar al enfermo a no caer en las posibles tentaciones con las que el maligno tentaría la voluntad del agonizante, era esencial para lograr el objetivo principal, no salvar la vida del agonizante, sino salvar su alma para la eternidad. Por contra, una muerte rápida, sin agonía, era un mal síntoma para la salvación del alma.

Una vez que el hermano hubiese fallecido, los clérigos, hermanos, hermano mayor y diputados debían comunicar al muñidor de la Hermandad que apercibiese y mandase llamar a todos los hermanos ${ }^{7}$. Éstos debían acudir con candelas para velar al difunto. Igualmente, debía acontecer si se trataba de la mujer de un hermano o «fijos o padre o madre si estuvieren a su misión o apaniaguado o criado de su casa y vamos todos rezando cada veyntevezes el paternostre y el avemaría por el ánima del hermano» ${ }^{8}$.

Era importante cumplir con los tiempos para el enterramiento del finado. Así las Constituciones Sinodales de Sevilla se establecía que «estatuimos, que no haya dilación en enterrar los difunctos, i que ninguno tengan por enterrar, más de veintiquatro horas, i los vicarios, i curas lo hagan assí cumplir...»"

Los hermanos quedaban obligados a acudir al sepelio y debían concurrir con candelas encendidas y rezando. Quedaban además todos los hermanos obligados en el día del enterramiento a asistir con los clérigos

«a las gracias a casa del tal difunto en la mañana y en la tarde durante las horas canónicas y responso y gracias y el hermano que no estuviere y esto no cumpliere o cumplir no quisiere pague de pena un quarentón de cera. Y a las gracias vayan a la mañana y no a la tarde» ${ }^{10}$.

Las reglas de la Hermandad de la Purísima Concepción y Ánimas Benditas de Bollullos contemplaba más o menos el mismo protocolo a cumplir de modo

«que el Hermano Mayor tenga noticia que haya fallecido algún hermano o hermana siendo vecino deste pueblo y constando hauer pagado todos sus reconocimientos como está dispuesto mandara la campanilla auisando la hora del entierro para que no tengan disculpa, loshermanos... an de tener obligación de asistir y acompañar el cuerpo hasta que quede sepultado y de ir a dar las gracias con el duelo... en el entierro irán rezando como especialmente obligados para contemplar piadosamente el alma de su hermano defunto en el gremio de las

7 La obligada asistencia de los miembros de una hermandad a los sepelios de sus hermanos o familiares debió ser la norma general en muchas cofradías. Así, en las Antiguas Reglas de la Hermandad de la Soledad de Sevilla, también se recoge esta obligación en uno de sus capítulos. Véase CAÑIZARES JAPÓN, Ramón: Las Antiguas Reglas de la Hermandad de la Soledad de Sevilla. Sevilla, Ed. Hermandad de la Soledad y Real Maestranza de Caballería de Sevilla. 2014. Págs. 65-66.

8 Reglas de la Hermandad de la Misericordia de Bollullos Par del Condado. Op. Cit.

9 Constituciones Sinodales de Sevilla. Título De sepulturis.Capítulo II.

10 Se le llamaba "las gracias" al momento de dar el pésame a los familiares, a lo que éstos respondían dando las gracias por el acompańamiento en el duelo. 
Benditas del Purgatorio luego que se llegue a la casa donde está el cuerpo. El Hermano Mayor señalará quatro hermanos que lo lleuen y si fuere el defunto hermano de otra cofradía, nombrará dos cada una, y los que fueren nombrados deuerán hacerlo; assí por que se les convida a una obra charitatiua y meritoria como por euitar el escándalo...»" ${ }^{11}$.

Resulta interesante que se contemple aquí el hecho, que debía ser algo frecuente, de que la persona fallecida perteneciese a varias hermandades. De ese modo, según estas reglas, los gastos del sepelio y las distintas obligaciones para con el hermano fallecido, debían ponerse de común acuerdo entre las hermandades.

En el caso de la Hermandad de la Misericordia de Bollullos, el hermano mayor y los diputados elegían a seis de entre los hermanos para que abriesen la sepultura y todos tenían la obligación de tomar las azadas para soterrar el cuerpo. Con ello, se representaba el cumplimiento cristiano de enterrar a los muertos. Quedaban obligados a decir tres misas por el alma del hermano o por la de su mujer, pero no así

«por fijos ni por criados ni paniaguados ecepto por el tal hermano o hermana muger del hermano el primero día de su enterramiento una misa cantada y dos rezadas por el ánima del tal hermano difunto y las tales misas pague la hermandad a los clérigos de la limosna y sea pagado por las dichas tres misas a los clérigos curas de la iglesia donde fuere enterrado el difunto cinquenta maravedíes» ${ }^{12}$.

En el caso de la Hermandad de las Ánimas de Manzanilla, el número de misas obligadas a decir por el difunto para el bien de su alma y su salvación eterna era de seis, en la que una de ellas debía hacerse en la Capilla de Scala ${ }^{13}$ de la Catedral de Sevilla que debía contar con algún tipo de bula que favoreciese al alma del finado ${ }^{14}$. Resulta importante el papel de las Cofradías de Ánimas Benditas del Purgatorio, de hecho, entre los siglos XVI y XVIII, las cofradías relacionadas con las almas del purgatorio estaban presentes en la práctica totalidad de las parroquias.

Las cofradías de las Ánimas Benditas del Purgatorio tenían como origen la clemencia, por los que se han quedado a medio camino entre el Cielo y el Infierno: en el Purgatorio.

11 A.D.H. Leg. 116, Bollullos Par del Condado, Regla de la Cofradía y Hermandad de la Purísima Concepsión y Ánimas Venditas de la Villa de Bollullos del Condado. 14 de julio de 1747. Cap. 16.

12 Reglas de la Hermandad de la Misericordia de Bollullos Par del Condado. Op. Cit.

13 La Capilla de Scala de la Catedral de Sevilla recibe el nombre de su patron, Baltasar del Río, Arcediano de Niebla, fundador de la cofradía de Nuestra Señora de Consolación y de los Doce Apóstoles y Obispo de Scala. Después de patrocinar la capilla y su enaltecimiento falleció el 1 de enero de 1541 en Roma, y a pesar de dejar testamentado su deseo de ser enterrado en la capilla hispalense, fue finalmente sepulado en la iglesia de Santiago de los Españoles de Roma. Por lo que finalmente su cenotafio hispalense está sin ocupar.

14 A.D.H. Sig. Antigua: Palma, Hermandades, Legajo 4.:Regla de la Cofradía de Ánimas de Purgatorio de la iglesia de Santa María de Manzanilla. CAPÍTULO XIX. Que trata de las misas que se an de dezir a los hermanos y a sus mugeres y a hermanas cofrades cuerpo presente. 
Para los casos en que el difunto no tuviese la capacidad económica para sufragar las misas necesarias para la salvación del alma del finado, es la propia Cofradía de Ánimas la que solicita y costea las misas y plegarias necesarias para liberar esas almas en pena y puedan alcanzar la Gloria Eterna.

El motivo por el que este tipo de cofradías tuvieron gran éxito de hermanos en esos siglos, no es más que el interés de los propios hermanos por su propia salvación. Pues con la pertenencia a dicha hermandad se garantizaba no solo la intercesión de sus hermanos mediante oraciones y misas por la salvación de su alma sino que también contribuían con una buena obra moral que le sería valedera a la hora del Juicio Final.

«Y porque esta nuestra bocaçión es de las Ánimas de Purgatorio, y nuestra madre la santa Yglesia tiene de costumbre con sus sacrificios suplicar a Dios Nuestro Señor por el perdón de todas las Ánimas de Purgatorio, a quienes nosotros los cristianos hermanos de la santa Cofradía tenemos por abogadas, ordenamos y tenemos por bien que el primer sábado por la tarde pasado el día de Todos Santos o quando fuere acordado por nuestro cabildo y luego el domingo siguente seamos obligados todos los cofrades desta dicha Hermandad hazervna fiesta de Todos los Santos general, solene con sermón, por todas las Ánimas de Purgatorio en la yglesia de Santa María desta dicha villa donde es abitaçión. Para lo qual nos juntemos todos los cofrades, siendo primero llamados por nuestro muñidor, por mandado del prioste, dos días antes que se a de selebrar la dicha fiesta. Y todos juntos estén en la dicha yglesia antes de que se començaren las Bísperas. Y mientras se diga la Magnificaty oraçión tengan las velas ençendidas. Y ninguno de los dichos cofrades que vinieren a las Bísperas y missa no sea osado de salir de la dicha yglesia hasta ser acauados los diuinosofiçios. Y el cofrade o cofrada que fuere llamado para la dicha fiesta y no viniere pague de pena por cada vez, medio real para la çera de nuestra Hermandad, si no diere escusa ligítima. Y este domingo por la tarde se diga vna Vigilia de difuntos a la qual asistan todos los cofrades con la mesmaobligaçión que el sábado y domingo por la mañana. Y luego el lunes siguiente se diga su missa cantada con sus ministros y capas, a la qual se hallen los hermanos que quisieren y digan seis missas de requien rezadas por las dichas Ánimas de Purgatorio, o más missas si ouieredispusición y se acordare por nuestro cabildo. En cada vna de las quales salga el saçerdote con su responso a la tunba, la quala de estar en medio de la yglesia con su paño negro y seis hachas de çera, y la cruz alta de la yglesia y nuestro cruçifixo desde el sábado a las primeras Bísperas. Y acabada la missa mayor salgan con sus responsos como dicho es y así mesmo por el çimenterio de la dicha yglesia. Y en el sábado o en el domingo sean obligados todos los hermanos y hermanas a rezar çinquenta Ave Marías y çincoPaterNostres, que es la terçia parte del rosario, por las Ánimas de Purgatorio»" ${ }^{15}$.

15 A.D.H. Sig. Antigua: Palma, Hermandades, Legajo 4.:Regla de la Cofradía de Ánimas de Purgatorio de la iglesia de Santa María de Manzanilla.CAPÍTULO XIIII. Que trata de las fiesta general que se a de hazer de Todos Santos e difuntos. 
Muy interesante resulta esta descripción pues nos desvela como era la Función Solemne de la Hermandad que tenía lugar para el día de Todos los Santos. Costumbre que aún hoy se mantiene en la tradición cristiana, si bien, se ha rescindido del boato que acompañaba a la Función. En esa Función, como hemos visto, se disponía una tumba o ataúd en medio del altar -en algunas hermandades o instituciones aún se guarda esta costumbre-, a la que se le cubría con paño negro, y se rodeaba de seis hachones (segundillos o blandones) y la cruz alzada parroquial. Acabada la misa, el sacerdote en comitiva, salía al cementerio parroquial oficiando responsos en favor de los difuntos.Son muchas las cofradías que establecían de un modo u otro alguna función especial por sus difuntos por el bien de su alma:

«Hordenamos y mandamos que vn domingo adelante del día de la conmemoración de los difunctos, que es vn día después de Todos Sanctos, hagamos vna Vigilia el tal domingo en la tarde, y el lunes siguiente vnamissa cantada con ministros y ofrenda de pan y vino, lo mejor que pudieren. Y esta fiesta y remembrança se diga y faga en la yglesia mayor de esta villa de Haznalcóllar por nuestros hermanos biuos y difunctos. Para lo qualhazer y cumplir tengan cuydado los nuestros hermanos mayordomos y manden hazervn túmulo, el mejor que nos sea pusible, y en él pongan velas y alrededor las hachas puestas de nuestra Hermandad y Cofradía. Y que si los nuestros mayordomos vieren que no ay harta cera, se haga vn cabildo antes para que se dé horden y se prouea toda la que faltare, y que el dicho túmulo tenga la Cruz de la tal yglesia alta y junto con la dicha Cruz esté el estandarte y seña de nuestra Cofradía. Y para la tal fiesta de Vigilia y onrras sean muñidos en general todos los hermanos. Y el que faltare y no viniere pague de pena vn real para la cera que se gasta en la tal vigilia y missa» ${ }^{16}$.

También a veces, estas hermandades de ánimas costeaban la construcción y mantenimiento de algunas bóvedas de enterramientos para los hermanos difuntos o para osario de otras personas cuyos medios no podían costearse un enterramiento individualizado.

La oración por la salvaguarda de las almas del purgatorio era obligación de todos los hermanos de las hermandades y debía estar presente a lo largo de todo el año. Así se establece en el Capítulo XV de la Regla de la Hermandad de las Ánimas de Manzanilla

«Que trata de la missa que se a de dezir todos los lunes de todo el año por las Ánimas de Purgatorio:

Yten, hordenamos y mandamos que cada lunes de todo el año se diga en la yglesia de Santa María vnamissa cantada y su proçesiónalrrededor de la yglesia por las Ánimas de Purgatorio, y se digan sus responsos y uayan con su çeraençendida

16 A.G.A.S.: Sección de Hermandades, legajo 183. Reglas de la Hermandad y Cofradía de Nuestra Señora de la Soledad. Aznalcóllar, 1590.CAPÍTULO XXVIII 
en ella los hermanos que hubiere y los demás que la quisieren llevar. Y si no se pudiere dezir esta missa el lunes se diga otro día siguiente» ${ }^{17}$.

Si algún hermano falleciese fuera de la villa, pero a menos de dos leguas de la misma y no tuviese a nadie de su familia que lo enterrase, la hermandad mandaría ir por él a cuatro o más hermanos para que lo trasladasen hasta la ciudad. Los demás miembros debían ir a recibir el cuerpo del fallecido con candelas encendidas desde la entrada de la ciudad hasta su lugar de enterramiento. Asimismo, si su familia determinaba conducirlo hasta su casa, «seale hecha honrra que por los hermanos está constituida de se fazer y quede la cruz de la misericordia ensima del tal hermano difunto ${ }^{18}$. Una vez fallecido el hermano, se le ofrecía al hijo mayor la posibilidad de ingresar en la hermandad sin tener la obligación del pago de la cuota inicial de cera que tenían estipulada. De igual modo que una vez fallecido un hermano, su viuda seguía siendo honrada como si el propio hermano siguiese vivo. No obstante, si ésta decidía volver a casarse, se la volvía a considerar ajena a la hermandad.

Las hermanas de la hermandad tenían la obligación de amortajar y acompañar al difunto. Todo ello, sin importar que el fallecido fuese hermano de la hermandad, pobre al cuidado del hospital o de cualquier otra parte.

Cuestión importante es el cómo se desarrollaba el sepelio. Por lo general, no existían ataúdes, tan solo unas sábanas y unas andas propiedad de la parroquia. El uso del ataúd se generalizó muy tardíamente. Las andas iban provistas de una tumba de madera y sin tapa. La caja del sepelio era también de propiedad parroquial o bien de alguna hermandad ${ }^{19}$ y se recuperaba tras depositar al difunto en la sepultura definitiva. Cruces, sábanas y andas eran tambiénelementos esenciales de las cofradías. Por tanto, no es raro encontrarlos en los numerosos inventarios de las hermandades ${ }^{20}$.

«Cap. 17.- Ordenamosque se tengan siempre existentes dos cirios de quatro o sino libras cada uno para que con ellos se alumbren los cuerpos defuntos de nuestros hermanos y hermanas los que se pondrán y ensenderán luego ante el cuerpo en la yglesia todo el tiempo que durare la vigilia,... fuere el entierro por la mañana hasta que al cuerpo se le de sepoltura.

Cap. 18.- Ordenamos que no solo se les de a nuestros hermanos y hermanas la honrra de su entierro las ynsignias y férretro, sin ynterés de limosna alguna por ser

17 A.D.H. Sig. Antigua: Palma, Hermandades, Legajo 4.:Regla de la Cofradía de Ánimas de Purgatorio de la iglesia de Santa María de Manzanilla. CAPÍTULO XV. Que trata de la missa que se a de dezir todos los lunes de todo el ańo por las Ánimas de Purgatorio.

18 Reglas de la Hermandad de la Misericordia de Bollullos Par del Condado. Op. Cit.

19 "Otrosi, hordenamos que el cruçifixo o paño o caxao otra qualquier cosa de nuestra Cofradía no la pueda prestar el prioste ni otra persona alguna para entierro, so pena de vna libra de çera”. En A.D.H. Sig. Antigua: Palma, Hermandades, Legajo 4.:Regla de la Cofradía de Ánimas de Purgatorio de la iglesia de Santa María de Manzanilla. CAPÍTULO XL. Que trata del cruçifixo y recaudo de la Cofradía que tubiere, no se pueda prestar.

20 MARTÍNEZ GIL, Fernando: Muerte... Págs. 400-405.

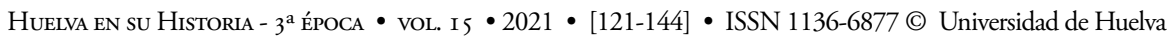


de cajas propias desta cofradía y la precisa asistencia de nuestros hermanos como queda dispuesto si también quatro misas rezadas...»"

Los fallecidos eran llevados sobre las andas, con los pies por delante y transportados por eclesiásticos o seglares según fuera la condición del difunto. Si bien, en el caso de la Hermandad de la Misericordia parece constatarse que eran sus hermanos los encargados de portear las andas del sepelio. De esta forma, los cortejos funerarios conformaban una variada composición: la luz de las candelas o hachones, el sonido de las campanas y la música cuando el fallecido era persona ilustre, miembros de las hermandades, clérigos, frailes, niños, pobres, plañideras, la propia familia y ciudadanos que acudían a acompañar al difunto o a presenciar el espectáculo ${ }^{22}$. Las candelas abrirían el cortejo funerario y a ésta seguiría la cruz parroquial. Tras ésta, al cuerpo de las hermandades seguidas del clero y tras ellos, el propio difunto ${ }^{23}$

Vemos pues todos los elementos que caracterizan los sepelios en el ámbito de la corona castellana. El carácter público, los lujos, los excesos, la ostentación de las riquezas de una familia, las andas para el transporte del difunto, las antorchas, las plañideras, la tipología procesional que adquiere el enterramiento, y otros muchos aspectos que asemejan a nivel europeo lo analizado para el territorio español.

Entre las obras de misericordia que estaban obligados a cumplir, una era sepultar los muertos especialmente los pobres. Debían hacerse cargo de aquellos miserablesy desvalidos que fallecían tanto en los hospitales o mesones, así como también aquellos que perdían la vida ahogados en los ríos ${ }^{24}$, en los campos o a manos de la Justicia.

«Por ende, establecemos que cuando quiera que alguno de los tales pobres fallesciere en nuestro hospital o en otro qualquiera hospital o en término desta villa fasta dos leguas de distancia, que la sancta hermandad vaya por él, y si allá fuere fallada alguna ermita o iglesia donde el tal pobre fuere enterrado en sagrado que lo entierren los tales hermanos que por el fueren y si no que sea traído a la villa y sea enterrado noblemente con mucha honrra con candelas encendidas y le digan una misa cantada con su responso o rezada como el hermano mayor quisiere y diputados determinaren y el hermano que al enterramiento de lospobres no viniere pague en justa pena media libra de cera ${ }^{25}$.

21 A.D.H. Leg. 116, Bollullos Par del Condado, Regla de la Cofradía y Hermandad de la Purísima Concepción y Ánimas Venditas de la Villa de Bollullos del Condado. 14 de julio de 1747. Cap. 17 y 18.

22 MARTÍNEZ GIL, Fernando: Muerte ... Págs. 400-405.

23 Constituciones Sinodales de Málaga. Año de 1671. Pág. 88.

24 Este detalle de que se hiciesen cargo de los fallecidos en ríos parece denotar que tal punto de su regla lo estaban tomando de alguna otra hermandad, pues no existen ríos importantes en el término de Bollullos Par del Condado, salvo pequeńos arroyos donde difícilmente podemos concebir que pudiera haber algún ahogado.

25 Reglas de la Hermandad de la Misericordia de Bollullos Par del Condado. Op. Cit. 
Otra opción para ser enterrado con el boato y solemnidad propia de la hermandad sin necesidad de ser hermano de ésta o pobre, era a través del pago de un canon que se cifraba en 1500 maravedíes, hecho lo cual,

«le sea hecha honrra cumplidamente como a qualquiera de los hermanos y si fuere pobre y se encomendare a la sancta hermandad de la misericordia sea hecha honrra muy cumplidamente tanto quanto mejor se pudiere fazer ${ }^{26}$.

En Bollullos, como en cualquier villa, la muerte se hacía visible en la sociedad, se convive con ella y se manifestaba en torno a ella evidentes signos de piedad que aparecen recogidos en los distintos capítulos de la regla de la Misericordia de 1579 . Si bien, con el transcurrir de los años y con motivos de la obligada reforma promulgada por la Corona a finales del siglo XVIII, se hacen algunos cambios con respecto a las costumbres de enterramiento de la Hermandad, pero en lo sustancial siguen manteniendo las muestras de piedad que les eran propia:

«...Acaecido el fallecimiento de algún pobre en el hospital o en el pueblo, y su término, que no tenga quien cuide de darle sepultura dando de ello aviso a el hermano mayor, se le hará entierro de charidad en la capilla de la Hospitalidad combocando a este fin a todos los hermanos en la misma disposición y forma que si fuese uno de ellos a quien se le tratace de hacer su funeral.

Quando en esta villa ocurra una común calamidad se socorrerá por la misma hermandad a proporción de lo que sus fondos permitan instituyéndoce para ello el hermano maior para aquellos medios mas oportunos de la certeza de la necesidad que se reprecentacuios oficios son los mismos que ha estado exerciendo esta hermandad desde el inmemorial tiempo de su creación $»^{27}$.

Queda claro a través de estas reglas, que se cumplía en la hermandad todas las costumbres del arsmoriendi del buen cristiano que hemos tenido ocasión de analizar anteriormente mediante las pinceladas que se han trazado a través de la literatura y las artes: la piedad, el deseable proceso agonizante, la presencia de público, el drama de la muerte, el intento de control de los excesos tanto de lujos como de las manifestaciones de duelo, pero sobre todo, las obras de misericordia y caridad para con los pobres y los nińos expósitos. Era la lucha por ganarse un alma más para la vida eterna, de ahí que antes de conducir a los niños expósitos al convento de Villalba, eran bautizados por si en el tra-

26 Reglas de la Hermandad de la Misericordia de Bollullos Par del Condado. Op. Cit.

27 Reglas de la Hermandad de la Misericordia de Bollullos Par del Condado. Firmada a 31 de octubre de 1785 siendo Hermano Mayor Pedro Borrajo y Juan Díaz Merchante y Casimiro López Diputados. Archivo Histórico Nacional. Consejos, 31308. Exp. 1. Una vez aprobada la reforma por el Real Consejo, la Junta de la Hermandad de la Misericordia presenta en el Arzobispado Hispalense las nuevas Reglas aceptadas por la Junta por común acuerdo de 12 de octubre de 1785. Archivo Diocesano de Huelva. Leg. 2 No 24. 
yecto falleciesen, su alma se salvaría para gozar de la gloria de Dios. El acompañamiento y las visitas al enfermo tenían el mismo propósito: la salvaguarda del alma, ayudar al agonizante, pobre o no, para que las tentaciones que le pudiesen sobrevenir en sus últimos momentos no malograsen su alma para obtener la salvación.

Era obligación de los miembros de las hermandades el acompañar al enfermo en esos difíciles momentos. En la Regla de las Ánimas de Manzanilla se recoge:

«Yten, hordenamos y mandamos que si algún hermano o hermana estubiere en articulo mortis que se le enbíe su candela con que muera. Y si pidiere que le aconpañen dos hermanos el prioste los señale, con pena de dos re- ales si no quisiere $\mathrm{yr} »^{28}$.

Otros capítulos de las Reglas, aparte de los que señalaban el funcionamiento interno de la hermandad, iban también encaminados a la piedad y misericordia para con el prójimo. La preparación del alma a lo largo de la vida siguiendo los postulados de los capítulos de la Regla, no es más que el reflejo de la necesidad de tener el alma preparada en todo momento, pues no se sabe cuándo nos llegará la hora del juicio en la que ésta será juzgada, e inspirados en el tópico literario del Ubisunt ${ }^{29}$, expresado magistralmente por Jorge Manrique en las Coplas a la muerte de su padre(1476) y, fray Luis de León en su Oda a la vida retirada (hacia 1583).

\section{MORS MORTEN SUPERÁVIT. LOS ESPACIOS DE ENTERRAMIENTOS}

«Que todos los cuerpos encerrados en urnas o sarcófagos, sobre el suelo, sean levantados y depositados fuera de la ciudad ${ }^{30}$.

Las Leyes del Fuero Juzgo, ${ }^{31}$ no sólo impedían el entierro de los cadáveres en las iglesias, sino también en los cementerios situados cerca de los centros urbanos, señalando para este menester los campos ubicados en las afueras de la ciudad. Las diversas leyes promulgadas por nuestros monarcas a lo largo de la historia trataban de regular el sistema de enterramientos dando un cuerpo jurídico que había de acatarse de manera estricta. De este modo se expresa en las Partidas del Rey Alfonso X:

28 A.D.H. Sig. Antigua: Palma, Hermandades, Legajo 4.:Regla de la Cofradía de Ánimas de Purgatorio de la iglesia de Santa María de Manzanilla.CAPÍTULO XVI. Que trata de lacandela que se a de enbiar al hermano questubiere en el artículo mortis.

29 Viene de la frase en latín Ubisuntqui ante nos in hoc mundo fuere? (¿Dónde están o qué fue de quiénes vivieron antes que nosotros?)

30 ARIES, Ph.: El hombre ante la muerte. Madrid. 1985. Pág. 33.

31 Código elaborado en Castilla en 1241 por Fernando III y que constituye la traducción del LiberIudiciorum del año 654 promulgado en la época visigoda 
«...por ende fue ordenado por los Padres Santos, que ouiessen sepulturas los cuerpos cerca de sus Eglesias, e non en los logares yermos e apartados dellas, yaciendo soterrados por los campos, como bestias. Y continua definiendo sepultura: es logar señalado, para soterrar el cuerpo del ome muerto. E sepultura tomo este nome de sepelio, que quiere decir, que meter so tierra....”

Asimismo, señala que los clérigos no debían demandar precio alguno por los oficios del enterramiento, aunque si era lícito el recoger alguna limosna por ello. Si bien, sí que se podían comprar los sepulcros, siempre que no hubiese algún hombre ya enterrado en él, pues podría caer en pecado de simonía ${ }^{32}$. Por último, señala que

«aquella tierra que es comprada, o dada para fazer Cementerio: e esta manda santa Eglesia, que non sea ninguno soterrado en ella, fueras ende aquel o aquellos cuya fuere $»^{33}$.

Las razones esgrimidas para la ubicación de los cementerios cerca de las iglesias iban desde que con ello los cristianos estaban más cerca de Dios, hasta que la cercanía a los vivos hacían que éstos recordasen y orasen por sus parientes o amigos. Asimismo, señala que así los difuntos podían ser encomendados mejor a los santos a los que estaban dedicados las iglesias y además con la cercanía a éstas se pretendía que

«los diablos no han poder de allegar tanto a los cuerpos de los omes muertos, que son soterrados en los Cementerios, como a los otros que están defuera... Pero antiguamente los Emperadores, e los Reyes de los Christianos, ficieronestablescimientos e leyes, e mandaron que fuessen fechas Eglesias, e los cementerios, fuera de las Cibdades e de las Villas, en que soterrassen los muertos, porque el hedor del non corrompiesse el ayre, ni matasse los biuos».

Eran conscientes pues del mal olor y los diversos perjuicios que los cadáveres causarían en los entornos eclesiásticos y aún más, intuían que de algún modo, ese ambiente insalubre era perjudicial para la salud humana.Serán los obispos los encargados de señalar los espacios que se debían dedicar a cementerio de tal modo, que se trataba de

«Eglesias Catedrales o ayan cada una dellasquarentapassadas a cada parte para Cementerio, e las Parroquias treinta. Pero esto se deue entender en esta manera: su fueren fundadas en tales lugares, que non pelo embarguen Castillos, o casas que estén muy cerca dellas: e este Cementerio deue amojonar el Obispo, cuando

32 La simonía es, en el cristianismo, la pretensión de la compra o venta de lo espiritual por medio de bienes materiales. Incluye cargos eclesiásticos, sacramentos, reliquias, promesas de oración, la gracia, la jurisdicción eclesiástica, la excomunión, etc.

33 Alfonso X, Rey: Las Siete Partidas del Sabio Rey D. Alonso el Nono. Ed. Facsímil de la Ed. de la de 1555. 
consagrare la Eglesia, segund la quantia sobredicha, si non ouiere embargo que pelo tuelga. E porque algunos dubdan, en como se deuen medir los passos, para amojonar el Cementerio, departelo Santa Eglesia en esta manera: que en la passadaaya cinco pies de ome mesurado, e en el pie quinze dedos de trauieso ${ }^{34}$.

Los difuntos debían enterrarse en el cementerio perteneciente a aquella iglesia en donde hubiesen sido parroquianos, en donde habían ido a orar y recibir los Sacramentos cuando estaban vivos. Si bien, había la posibilidad de poderse enterrar en la Catedral o en otra iglesia donde su linaje tuviese sepultura propia. Se establece además qué clase de personas podían ser enterradas dentro de las iglesias y quienes debían ser enterradas en los cementerios. De esta forma, dentro de las iglesias sólo podían enterrarse los reyes y reinas, sus hijos, obispos, priores, maestros, comendadores, prelados de las órdenes conventuales, los ricos-hombres, aquellos hombres honrados que levantasen una nueva iglesia o monasterio, a todos los clérigos o legos que por su santidad lo mereciesen por su vida y sus buenas obras. Todos los demás cristianos serían enterrados en el cementerio parroquial. Naturalmente, de todo esto se excluían a los musulmanes, judíos, herejes, y en general «a todos los otros que non son de nuestra Ley». Además, quedaban excluidos también los ladrones, excomulgados por causa mayor, usureros, etc.

Transcurridos muchos años, después vemos parecidas advertencias en las reglas formadas por la Hermandad de las Ánimas Benditas de Bollullos en 1747:

«Ordenamos que no pueda ni deua ser auido por nuestro hermano persona alguna que tenga raza de judío, moro, herege, recién conuertida a nuestra Santa Fe baptizada... beruerisco, negro, mulato, exclauo,... $»^{35}$.

El rey Alfonso X, en la Primera Partida, establece legalmente que las personas puedan ser enterradas dentro o fuera de los templos, dependiendo de su categoría o clase social, sin duda, impulsado por el arraigo de esta práctica. Asimismo, se establecía el modo en que debían ser enterrados. Si se trataba de gente humilde no debían enterrarse con ninguna muestra de riqueza o joyas pero si por contra era de la realeza, nobleza o clero, éstos debían ir acompañados por los ornamentos y hábitos que le fueron propios ${ }^{36}$. Justificaban esta medida en que las riquezas enterradas no beneficiaban en nada a los vivos, si bien, parece que no les importaba demasiado las riquezas que pudiesen enterrarse con las personas más pudientes.

34 Alfonso X, Rey: Las Siete Partidas...

35 A.D.H. Leg. 116, Bollullos Par del Condado, Regla de la Cofradía y Hermandad de la Purísima Concepsión y Ánimas Venditas de la Villa de Bollullos del Condado. 14 de julio de 1747. Cap. 23

36 LOPEZ, G.: Las Siete Partidas del muy noble Rey Don Alfonso el Sabio.Tomo I. Madrid. Compañía General de Impresores y Libreros del Reino. 1843. Título XIII. Págs. 249-261. 
Con el tiempo, la generalización de estas prácticas, hizo que las iglesias dejaran de ser únicamente el lugar de encuentro para la liturgia, la misa y el culto a los santos para convertirse en punto de referencia, cita y encuentro de la vida y la muerte.

La costumbre de enterrar a los muertos en las Iglesias, se consolida por razones religiosas y económicas a lo largo de la historia de la cristiandad. Se pensaba que los enterramientos en el interior del templo facilitaba el recuerdo de los muertos y favorecía la intercesión de los santos para con los difuntos. La Iglesia apoyaba esta práctica ya que, a la vez que confortaba a los creyentes, constituía una muy buena fuente de financiación para las arcas eclesiásticas ${ }^{37}$.

La venta de espacio o capillas en los templos parroquiales constituyó una fuente de ingresos para las cuentas eclesiásticas. Mediante estos mecanismos se fueron completando la fábrica de los templos parroquiales, mediante la levantamiento de capillas adosadas a sus muros o la erección de ermitas ${ }^{38}$.

Otro factor determinante en el proceso de cohabitación de muertos con vivos, fue el hecho de que, con el tiempo, los enterramientos de santos importantes motivasen el desarrollo de grandes centros de peregrinación, que terminaría generando un crecimiento urbano en torno a las basílicas y monasterios. Los muertos, mezclados ya con los habitantes de estos núcleos de población, fueron introducidos de esta forma en el corazón histórico de las ciudades. En adelante ya no hubo parte alguna de iglesia que no recibiera sepulturas y esta relación entre iglesia y cementerio se estableció definitivamente. Pronto la tumba se consideró un lugar consagrado donde era posible celebrar la liturgia y que más tarde se llamará capilla ${ }^{39}$.

El hecho de que en las iglesias se siguiesen enterrando hasta finales del siglo XVIII motivó que el pavimento de las parroquias estuviesen casi por completo formado de losas o piedras tumbales. Muchas de estas lápidas llevaban monogramas, fechas, armas, escudos familiares o la representación de algunos instrumentos identificativos del trabajo que desarrolló el difunto en su vida.

Los entablamentos que solaban las parroquias conseguían dar uniformidad al solado pues el subsuelo llegaba a quedar completamente fragmentado y compartimentado. Sirva de ejemplo, el aspecto que hoy podemos observar en la Iglesia Mayor Abacial en el Castillo Fortaleza de la Mota de Alcalá La Real en Jaén. Además de este entablamento, el suelo se solía cubrir con esterados que ocultaban el compartimentado aspecto del solado parroquial. Son numerosísimos los casos de todas las parroquias en los que nos encontramos en sus cuentas y a lo largo de los siglos los gastos ocasionados por la sustitución del esterado pues las pisadas, la humedad y el paso del tiempo deterioraban rápidamente estas esteras.

No obstante, a decir verdad, sólo los eclesiásticos o personas poderosas podían conseguir ser enterrados en los interiores de las iglesias -y a ser posible lo más cerca que

37 FERNÁNDEZ GRUESO, M.: De cementerio a camposanto. 2007.

38 FERNÁNDEZ GRUESO, M.: De cementerio a camposanto. 2007.

39 ARIES, Ph.: Op. Cit. Pág. 41. 
se pudiera del altar mayor, bajo el arco toral, o junto a alguna reliquia- ${ }^{40}$, tal como ya se establecía en las Partidas. Por contra, la inmensa mayoría de la población tenía que conformarse con el enterramiento en el atrio o porche de las parroquias e, incluso, los pobres ni siquiera eso, teniendo que resignarse con ser enterrados en las fosas comunes que normalmente eran subvencionadas y cuidadas por alguna hermandad; es este atrio el que más tarde se convertiría en el cementerio propiamente dicho.

En el caso de las personas más pudientes como los nobles u obispos solían construirse lujosos espacios de enterramientos que pueblan toda nuestra geografía nacional. Algunos podían costearse la elaboración de sus propias capillas. Tenemos magníficos ejemplos, como la Capilla del Condestable de la Catedral de Burgos u otras que aunque más sencilla en su concepción también resultan francamente interesante como la que podemos observar también en la Catedral de Burgos dentro de Capilla de San Gregorio adosado al muro norte, el sepulcro del obispo D. Gonzalo de Hinojosa, que murió en el año 1237. Los relieves del sarcófago presentan motivos alusivos a la muerte y a la liturgia funeraria del Obispo bajo dosel gótico corrido. Sobre él, sobresale la figura yacente del Obispo, vestido de pontifical. Sobre el mismo sepulcro aparece la inscripción histórica de la concesión de Altar Privilegiado. Por citar solo alguno más cercano cabe destacar el sepulcro de Don Pedro Portocarrero (VIII Señor de Moguer en el Convento de Santa Clara de Moguer, Huelva.

Poco se sabe sobre el aspecto que presentaban dichos cementerios anexados a las parroquias. En su mayoría se quitaron para dejar los alrededores parroquiales libres de ese aspecto desagradable que envuelve todo lo relacionado con la muerte. Apenas nos quedan unas breves descripciones sobre su primitiva fisonomía. Por ejemplo, en un reconocimiento de la iglesia de Santa María de Sanlúcar la Mayor (Sevilla), hecho por Ambrosio de Figueroa en 1771, para el arreglo del mismo, se dice:

«...assimismo el Porche de la referida yglesia está enteramente destruido por hauerse abierto por distintas partes hoyos profundos de forma que con dificultad se puede transitar por él... por lo que respecta al Porche dixo que es mui cierto el ser necesario su redificación por estar todo su mayor parte desmolido y ser preciso acauarlo de desmoler, poniéndolo todo a la plezo de la solería que oy tiene, bolviéndolo a formar de ladrillo y medio de grueso con buena cal y arena, aprovechando todo el material que del saliere, labradas sus paredes, mui delgados los tendeles de mescla y fraguados con bastante agua, lo que se labrará hasta la altura de una vara de alto; acordelados y atiranttados todos a un gruezo que oy se hallan aunque ruinosos unos más gruezos que otros, y se componen sus líneas que son quatro de sientto y ochenta varas, en que era de parecer eldeclarante que sobre dicha altura, para cumplimiento de quatro tercias de alto, que será lo mui suficiente en lugar de rosca se le echarán unos sillares de piedra de Jerena de la

40 RIVAS ALVAREZ, J.A.: Miedo y piedad: testamentos sevillanos del siglo XVIII. Sevilla, 1986. Págs.144145. 
dura buena que ay del ancho de los dichos pretiles y tercia de gruezo, labrados por tres paramentos vistos, que son los dos lados y el plan de ensima que chaflanadas sus esquinas y sus juntas machigenbrad (sic) labradas con toda perfección y aseo y todo el referido pretil por dentro y fuera irá reuocado, quedando el material descubierto y en las entradas que quedaren para su uso que serán quatro, lleuará sus gradas a correspondencia del pezo que pidiere la calle, en una pedirá tres gradas y en otras una o dos, las que serán de la referida piedra, y estas si llegare el cazo de que Vuestra Señoría assi lo determine es menester que el que ajustare la referida piedra... ${ }^{41}$.

En 1528, se hizo la donación para este mismo atrio de unas cadenas que lo debían de circundar ${ }^{42}$. Por consiguiente, debió ser frecuente que los atrios lo componían un espacio cercado alrededor o en alguno de los lados de las parroquias, si bien el acceso a los mismos no suponía gran dificultad, e incluso el poder transitar o realizar diversas actividades en el mismo.

A partir del siglo XV, debido a la saturación de cadáveres que había en las iglesias, se tomó la costumbre de retirar de la tierra los huesos más o menos resecos de las sepulturas de más antigüedad y amontonarlos en unos osarios con el fin de dejar más espacio para los próximos enterramientos. Fue esta costumbre la que provocó que estos atrios, e incluso los interiores de las iglesias sufriesen un grave deterioro en su aspecto. El empleo de estas prácticas se incrementaba en los periodos de epidemias, épocas en las que, además, se solía enterrar en grandes fosas comunes debido a la inundación de cadáveres que se acumulaban en poco tiempo. Así pues, las parroquias se convirtieron en su interior y exterior en unos enormes cementerios que con las epidemias se sobrellenaban dando lugar a graves problemas de olores e inmundicias:

«...se advierte en las yglesias parroquiales de la falta de cuidado que ay pues se entierran los cadáveres, y no cierran inmediatamente las bóvedas y sepulturas como debe hazerse sino que las dexanentreaviertas por evitar el travajo que ofrece la repetición de actos que las actuales enfermedades que se experimentan han ofrecido dexándolo asi dos o tres días; y conosiendo la ciudad que este abuso puede tener fatales consequencias...» ${ }^{43}$.

La saturación de cadáveres en las parroquias provocó que en numerosas ocasiones se recurriese a enterramientos fuera de la delimitación parroquial. Así, por ejemplo, en la iglesia de San Roque en Sevilla, en 1780, su párroco pidió licencia para poder enterrar algunos cadáveres fuera de sus límites, en el sitio que llaman Puerta del Osario ${ }^{44}$. Este

41 A.G.A.S. Sección III, Leg. 2741. Año 1771.

42 A.P.N.S.M. Sanlúcar la Mayor. Leg. 1128, Año 1528. Escribano: Antonio de la Palma.

43 A.H.M.S. Sección 5a. Tomo 145. Documento n¹4. Año 1785.

44 A.H.M.S. Sección 5a. Tomo 46. Expediente nº11.; MONTOTO, S.: Esquinas y conventos de Sevilla. 
hecho de las ampliaciones de los cementerios parroquiales, se vino repitiendo en Sevilla desde los siglos XV y XVI ${ }^{45}$, siendo una situación común en toda Europa; así en 1828, Marchant de Beaumont, describe los cementerios de París:

«...antiguamente todo era confusión, desorden, irreverencia hacia el descanso de los muertos en los cementerios de París. Una mano, enemiga del recuerdo, parecía que se esforzaba en acumular todo lo que fuese capaz de aumentar e inspirar el máximo horror. Lugares estrechos, húmedos, fétidos donde el sol sólo hacia presencia, fosas anchas y profundas en las que se acumulaban los cadáveres de los pobres por centenas, en tierras removidas y frecuentemente sumidas en el mayor abandono, murallas demolidas ante las cuales se amontonaban millares de esqueletos arrancados del seno de la tierra antes de ser reducidos a polvo... tales eran estos reductos a los que daban en París el nombre de cementerios ${ }^{46}$.

Los testimonios de denuncias sobre estos hechos se repiten a lo largo de muchos ańos, pero no es hasta la época de la Ilustración cuando empiezan a tomarse medidas sobre la legislación de los enterramientos ${ }^{47}$. Las medidas ilustradas supusieron con el tiempo el abandono del sistema de enterramiento en las iglesias y el surgimiento de los cementerios que actualmente conocemos. Si bien, estos primeros cementerios seguían gestionados por las diferentes parroquias, a las que se les había suprimido sus camposantos, aunque eso sí, estos nuevos cementerios estarían desde ahora ubicados en las afueras de las poblaciones.

En España, estas medidas fueron tomadas el 3 de abril de 1787 por la Real Cédula de Carlos III, en la que se prohibe severamente enterrar en las iglesias y se ordena la edificación de cementerios fuera de las ciudades ${ }^{48}$. El motivo de la decisión fue la epidemia que se inició en 1781 en la villa guipuzcoana de Pasajes que según opiniones de sectores cercanos al monarca, se originó por «...el fedor intolerable que exhalaba la parroquia, por los muchos cadáveres sepultados all $i{ }^{49}$.

Sevilla, 1973. Págs. 42-43.

45 VELAZQUEZ Y SANCHEZ, J. Anales epidémicos. Reseña histórica de las enfermedades contagiosas en Sevilla... Sevilla, 1866. Págs. 31-32.

46 MARCHANT DE BEAUMONT, F.M: Manuel et Itinéraire du curieuxdans le Cimetière du Père La Chaise, París, 1828. Págs. 24-25.

47 CABARRUS, Conde de: Cartas sobre los obstáculos que la naturaleza, la opinión y las leyes oponen a la felicidad pública, Madrid, 1820. Págs. 294-297, passim.

48 SUAREZ GARMENDIA, J.M.: Arquitectura y urbanismo en Sevilla durante el siglo XIX, Servicio de Publicaciones de la Diputación Provincial de Sevilla, 1986. Págs. 56-57.; GONZALEZ DÍAZ, A. "El cementerio español en los siglos XVIII Y XIX” en Archivo Español de Arte, no 169-172, Tomo XLIII, Madrid, 1970. Págs. 289-290.

49 REDONET, L.: "Enterramientos y cementerios". Boletín de la Real Academia de la Historia. CXX. Pág. 54. 
Sin embargo, fue una medida difícil de aceptar por la fuerte presión que ejercían tanto la inmemorial costumbre como las personas de gran poder económico que seguían viendo el hecho de ser enterrados en las parroquias, un aspecto más para la distinción social. Estas reticencias, junto con la grave crisis económica y de control político causado por la dominación francesa motivaron que el caduco sistema de enterramientos parroquiales se mantuviese en la mayoría de los casos hasta mediados del siglo XIX.

Aunque la decisión por parte del Gobierno se había tomado algunos años antes, la grave epidemia sufrida en 1800, despejó las posibles dudas sobre la imperiosa necesidad de llevar fuera de las ciudades los espacios de enterramientos. Numerosos son los testimonios sobre el miedo al contagio de la enfermedad y a la propagación de la misma a través de otros enfermos o de los cadáveres que llenaban las calles de la ciudad. Por ejemplo, en Sevilla la epidemia se introdujo a través de Triana a finales de julio, extendiéndose rápidamente por los otros barrios de la ciudad ${ }^{50}$. Por eso, sus aterrados habitantes abandonaban la ciudad marchándose a los pueblos del Aljarafe, más limpios en sus aires y con menores riesgos de contagios. Sin embargo, en contra de estos que intentaban huir de la muerte, se oponían las propias leyes de los diferentes pueblos a los que iban, así por ejemplo, en Sanlúcar la Mayor se recoge el siguiente testimonio:

«...en la ciudad de Sevilla, y Barrio de Triana cuyos vecinos han tomado el efugio (sic) de abandonar sus casas, y refugiarse a los pueblos inmediatos de los que vno es esta ciudad para probeer de remedio oportuno que corresponde y alibiar el vecindario de los tristes males que pueden sobrebenir cuando ya solo la benida de algunos sujetos tiene aflixido el vecindario... $\nu^{51}$.

Especialmente curiosa resulta la queja llevada al Ayuntamiento de Sanlúcar la Mayor por el Maestro de Primeras Letras, en la que se pone de manifiesto el pánico que generó la epidemia:

«...en atención a haverse enterrado, por disposición de la Junta de Sanidad en el corral de la casa inmediato a la de mi domicilio el cadáver de un hombre que en ella murió del contagio, ha resultado que algunos de los padres de mis discípulos recelando las funestas consequencias que haya de estar en la inmediación de una casa contagiadase (sic) pueden seguir a sus hijos me afirman no los enviarán a la escuela interín no mude de habitación...." ${ }^{52}$.

Resulta evidente en este documento, que en caso de contagio, los enterramientos podían hacerse en cualquier lugar, máxime cuando como en este caso el cementerio

50 RODRIGUEZ BARBERÁN, F.J.: Op. Cit. Págs. 52-53; WAGNER, K.: "La epidemia de fiebre amarilla en Sevilla”. ArchivoHispalense. No 181. Pag. 206.

51 A.H.M.S.M. Actas de Ayuntamiento de Sanlúcar la Mayor. Septiembre de1800. Leg. 19. Págs.64 y vta. 52 A.H.M.S.M. Actas de Ayuntamiento de Sanlúcar la Mayor. Septiembre de 1800. Leg. 19. Pág 111. 
parroquial se hallaba en pleno centro de la ciudad, que pese a todo, se siguió utilizando hasta mediados del siglo XIX. Por esos años, se llevó a cabo la desaparición de los camposantos de la fisonomía urbana, dando lugar, a la aparición de numerosas plazas y calles que hoy rodean a nuestras parroquias y que muestran, a veces, alguna cruz proveniente de su antiguo cementerio:

«...el señor alcalde segundo hizo presente a la corporación que ha visto que parte del alisar del Porche de la Yglesia de Santa María de esta ciudad se está destruyendo por orden del señor Presidente; más, como dicha medida la consideré poco conveniente al aspecto público de la población por el mal resultado que con solo destruir una pequeña parte cuando haciéndolo del todo, el templo como las casas que dan vistas al mismo y las plazas que lo rodean gozarian de una buena vista; y además le proporciona de mayor ensanche a la via por cuyas sircunstancias es de parecer que la municipalidad se fije en ello y acuerde lo que considere mas conveniente... a como mejor proporciona vista al templo, las vías públicas y casas inmediatas al mismo..." ${ }^{53}$.

No hay que olvidar la oposición de la Iglesia por considerarse despojada de uno de sus ingresos más importantes, y que conllevaba la pérdida de unos terrenos que pertenecían a la parroquia en favor de la corporación municipal. En esto, el clero veía el principio de la desaparición del orden de la relación sociedad-iglesia instituido desde hacía siglos ${ }^{54}$.

Las reacciones del clero no se hicieron esperar y sus quejas y lamentos por la nueva situación y la merma de sus ingresos, quedaron reflejados en multitud de escritos que hacían llegar a sus superiores, si bien, nada pudo parar el proceso que acabaría con la presencia de los cementerios en el interior de las ciudades.

«Muy señor mío y de todo mi afecto. No he podido contestar más pronto a su apreciable del 6 de enero actual, por haber tenido un catarro pulmonar hace un mes, que no me dejaba descansar de día y noche la tos, apéndice de un ataque de sangre que sufrí en octubre y que estuve sacramentado y para mi convalecencia me visitó doctor con este catarro tan fuerte.

Hoy que me hallo mejor me ocupo de contestar su contenido diciéndole a vsted, que puesto a que tiene concluidas las quentas del culto de mi yglesia de los que resultamalcanze a mí favor de 1.033 reales, y que de acuerdo con el vicitador no las pone vsted en limpio hasta que yo me decida a abonarle 318 reales, mitad de los derechos que importan, contesto con decir a vsted que ni tengo, ni puedo

53 A.H.M.S.M. Actas de Ayuntamiento de Sanlúcar la Mayor. 1871. Leg.28. S/p.

54 Vid Tesis de PELAEZ BARRANCO, Ma B.: La muerte en el ámbito urbano de la Sevilla bajomedieval (segunda mitad s.XIII-XV). 
en el día abonar dicha cantidad, por dos razones muy sencillas. $1^{\circ}$. Por el déficit que tengo de que nunca me reintegraré, y a mayor abundamiento, por haber pagado cada uno de los párrocos 400 reales del ynterdietas de despojo que por orden del prelado se le puso a el Alcalde de esta ciudad por haber derribado por su solo autoridad los porches de Santa Maria y de San Eustaquio, recurso que entablamos en este juxgado y que sabiamos iba a perderse porque la justicia solo está hoy en Dios, pero por obedecer al prelado las seguimos y se ha perdido con los gastos de 800 reales sobre fabricas.

$2^{\circ}$. Porque victoriosos de este acto, nos amenazan con frecuencia que hasta las parroquias se derribarán a voluntad de ellos si les place, habiendo perdido la influencia y prestigio para con el pueblo en términos que llegará día y no lejano, en que le entreguemos las llaves de los templos al prelado toda vez que han sitiado por hambre a los párrocos intrigando para que todo se le haga de pobre así en bautismos, como en funerales y casamientos. A este estado ha llegado esta población... Esto amigo mío se acaba. Siento decirlo, pero es preciso, toda vez que careciendo de pagas, hay que atender a la vida el que tiene alguna cosa, que los que carecen de recursos se mueren o piden limosnas " ${ }^{55}$.

En otros pueblos del Condado onubense, las edificaciones de cementerios alejados del casco urbano parece que se hicieron realidad en el primer cuarto del siglo XIX, si bien, la propiedad del cementerio aún permanecía bajo del dominio eclesiástico. Según consta en una carta oficiada por el Ayuntamiento Constitucional de Almonte junto con el cura de la localidad en noviembre de 1847 y dirigida al Intendente de la Provincia, y a la vez que se solicitaba el arreglo de algunas vigas de la techumbre de la Iglesia y de otras dependencias de la misma se hacía constar la necesidad de la reparación del cementerio, por lo que se desprende que éste ya debía tener algunos años:

«Las tapias, que cercan el cementerio de esta parroquia, que está fuera, y algo distante de esta población, se hallan vencidas sobre las mismas sepulturas, y apuntalada la plancha que cubre la puerta y el frontispicio que la corona a causa del mismo vencimiento. Creemos inútil no solamente el perjuicio que ha de causar la caída de esta cerca que debe verificarse muy pronto, sino también el disgusto público que con escándalo de toda la poblaciónhabrá de ocasionar el espectáculo tan desagradable, como indigno que ofrecerían los cadáveres desenterrados y acaso devorados por los perros y otros animales...» ${ }^{56}$.

55 A.P.S.M. Parroquia de Santa María. Sanlúcar la Mayor. Papeles varios. 1871

56 A.G.A.S., Sec. IC. Casas Parroquiales y Reconstrucción de Templos, Leg. 14552. Carta emitida por el Ayuntamiento Constitucional de Almonte y el Párroco Don Fernando Martínez Conde al Sr. Intendente de la Provincia de Huelva. 17 de noviembre de 1847. 
Con este motivo, en el reconocimiento efectuado por don Manuel de Zayas y Rivero $^{57}$, mandado por el Intendente de la Provincia de Huelva para verificar los deterioros denunciados por el Ayuntamiento y Párroco de la localidad de Almonte, se expresa diciendo:

«El Campo Santo de esta villa se haya en igual y aun mayor estado de ruina, pues la pésima cerca o tapia que hoy lo circunda, además de su mala fábrica y lo desplomada que se encuentra, no impide que los perros entren a devorar los cadáveres por lo que se hace indispensable labrar de nuevo tres de sus cuatro muros, el Cuarto del Guarda y el de los utensilios fúnebres, del que sólo quedan vestigios ${ }^{58}$.

En el diseño del nuevo cementerio se contemplaba los siguientes espacios: Vestíbulo o ingreso, cuarto del guarda, local para los nichos, osarios, enterramiento común, capilla, jardín de yerbas aromáticas y cuarto de los féretros. Todo según se dispone en el dibujo proyectado. El cementerio contaba con una valla de cuatro metros de alto y una cancela de hierro que da acceso al mismo. La construcción del mismo debió dilatarse en demasía a lo largo del tiempo pues en el reconocimiento de las obras del cementerio practicado antes de su conclusión en 1865, aún faltaba por construir el cuarto del guarda y el cuarto para guardar los utensilios fúnebres. Además, se manda hacer una zanja en el lado de la derecha que cogiese de ángulo a ángulo del cementerio. Dicha zanja debía ser de

«dos varas o más profundidad y siete pies de ancho para que paralelamente vallan colocando los cadáveres por hiladas llevando una tonga de tierra de media vara para cubrirlos y de modo que cuando entierran otro, lo ponen junto y le quitan la tierra dejando los restos diceminados; por estas razones... debe hacerse un osario o depósito donde se recojan todos los huesos que están dispersos pues no hay un sitio donde no se ponga un pie que no se pise uno..." ${ }^{59}$.

En el caso de Bollullos en la visita ejecutada en 1818 se denuncia que aunque la parroquia se

57 Profesor de Arquitectura por la Academia de Nobles Artes, Maestro Mayor de la Provincia de Huelva y de las obras de fortificación y edificios militares por el Cuerpo de Ingenieros del Ejército.

58 A.G.A.S., Sec. IC. Casas Parroquiales y Reconstrucción de Templos, Leg. 14.552. Reconocimiento del Maestro Mayor D. Manuel de Zayas y Rivero a la Parroquia y Cementerio de Almonte. 29 de enero de 1848.

59 A.G.A.S. Sec. IV, Casas Parroquiales y Reconstrucción de Templos, Leg. 14.552. Reconocimiento de José de Flores. 7 de agosto de 1865. 
«halla retechada de nuevo... el solado está indecentíssimo a causa de los enterramientos en ella. Se ha solicitado y convendría se verificase hazer un cementerio contiguo a la Yglesia.»"

De ello se deduce que siendo la Orden Real para la erradicación de los enterramientos parroquiales de 1787, aun en este año de 1818, Bollullos carecía de cementerio fuera del ámbito parroquial. Si bien, ya parece evidente que se habían vencido las reticencias morales y espirituales de ser enterrado fuera de las iglesias. Por contra, ahora lo ven como algo normal, habitual y hasta recomendable. No tenemos constancia de cuándo se llevó a cabo la construcción del cementerio, pero ya en 1842 se tiene constancia de algunos reparos efectuados en el mismo ${ }^{61}$.

Este cementerio en Bollullos tenía como peculiaridad que se llegó a construir sobre la bodega de los herederos de D. Francisco de Paula Morón ${ }^{62}$ pues entre 1850 y 1853 se registran los pagos anuales de su tributo.

El antiguo cementerio de Bollullos tuvo su momento de partida el 17 de octubre de 1851 donde se recoge

"que en vista de los espuesto por lo suplicantes y de los antecedentes del asunto autorizamos al presbítero Don Diego Valdayo, Mayordomo de la Fábrica de Nuestra Yglesia Parroquial de Bollullos del Condado para que proceda a la construcción del nuevo cementerio en aquella villa sugetándose al plano aprobado y a las leyes sanitarias que rigen en la materia, consultando la solidez y duración de la obra con la economía que debe guardarse en favor de los fondos de la fábrica, invirtiendo para ello los créditos que esta tenga anteriores a la aplicación de su caudal a los bienes del estado en 1841, con cuyos productos y la cantidad de cuatro mil reales que ha ofrecido anticipar en calidad de reintegro con los derechos de sepulturas, el cura de dicha yglesia Don Quintín Santos Romero se llebará a termino la edificación del cementerio, dándonos cuenta en su día para que precedido su reconocimiento sea bendita si a ello hubiere lugar. y de orden de dicho señor lo trasladó a V.V. para su respectivo cumplimiento».

En virtud de este documento se dio principio a la construcción del cementerio en el año de $1852^{63}$. Asimismo, en 1860 se recoge la compra del un cuadro para el retablo

60 A.G.A.S. Sec. IV, Visitas, Leg. 1452. Bollullos Par del Condado Santa Visita. Año de 1818. Escrutinio celebrado en esta villa. Entrada el día 12 de febrero de 1818 salida el día 22 de febrero de id.

61 A.G.A.S. Sec. IV, Libros de Cuentas, Leg. 288. Libro de erarios administrativos. 1841-1850.

62 Estuvo casado con dońa Antonia de Lerma y en el año de 1818 se registra que vivían separados pues la señora vivía en Gibraleón. Si bien, "jamás ha habido queja alguna ni de uno ni de otra. El es el más distinguido del pueblo, y ella habrá siete u ocho años que se fue enferma a casa de su hermana donde vive ejemplarmente". A.G.A.S. Sec. IV, Visitas, Leg. 1452. Bollullos Par del Condado. Santa Visita. Ańo de 1818. Escrutinio celebrado en esta villa. Entrada el día 12 de febrero de 1818, salida el día 22 de febrero de id.

63 A.G.A.S. Sec. IV, Libros de Cuentas, Leg. 288. Libro de erarios administrativos. 
de la iglesia o capilla que debió presidir este cementerio ${ }^{64}$ y un cuadro de las Ánimas que debió ocupar un lugar lateral de la referida capilla ${ }^{65}$. A pesar de ello, parece que en 1863 se debió acometer la construcción del nuevo cementerio o una profunda reparación en el mismo pues se llegaron a gastar en la edificación un total de 56.590 reales y seis maravedíes ${ }^{66}$. Y de nuevo, entre marzo de 1867 y septiembre de 1869 se vuelve a gastar 3.111 reales en la reparación del hundimiento de parte del cementerio y 1.804 reales en la construcción de 24 nuevos cañones ${ }^{67}$.

De algunos años después tenemos una descripción del mismo:

«Cementerio y su Capilla. Éste está cerrado por cuatro paredes angulares y mide próximamente cincuenta varas de largo por cuarenta de ancho. En su fachada hay una cancela de hierro con cerrojo y llave. En frente de ésta y sobre la pared opuesta está una Capilla reedificada recientemente, y sobre su fachada hay un campanario con una campana. Su techumbre es de armadura y por debajo cielo raso y su pavimento de loza de barro cocido. Tiene una sola nave y en su fondo hay un altar de material sobre el cual está un lienzo con caña dorada que mide sobre tres varas de alto y dos de ancho que representa el Calvario. Hay además en este cementerio un pozo con carrillo, cuerda, cubo y pila... ${ }^{68}$.

El hecho de que aun en 1907 el Sr. D. Francisco Neble y Delgado iniciase las conversaciones para levantar capilla enterramiento propiaen el solar que antes ocupaba el cementerio y que hoy ocupa la capilla, actualmente del sagrario: «terreno de mi corral, que linda con la dicha iglesia y que antes sirvió de cementerio» ${ }^{69}$, contiguo a la parroquia que sirviese de lugar de enterramiento para su "difunta hija, su esposa y los suyos» ${ }^{70}$, nos indica que aun los más destacados miembros de la sociedad ansiaban situar sus enterramientos familiares en el mismo espacio parroquial, a pesar, de que ya existiese en Bollullos un cementerio desde hacía más de medio siglo. Con ello, aun transgrediendo la Real Orden de 1787, la parroquia ve con acierto la licencia pedida por D. Francisco Neble, pues con ello, se conseguía ampliar el espacio parroquial y dar un mayor realce a la

64 Se llegó a pagar por este cuadro 2.800 reales.

65 Se llegó a pagar por este cuadro 153 reales.

66 A.G.A.S. Sec. IV, Libros de Cuentas, Leg. 288. Libro de erarios administrativos. 1 de julio de 1863 a fin de octubre de 1866 .

67 A.G.A.S. Sec. IV, Libros de Cuentas, Leg. 288. Libro de erarios administrativos. 1867-1869.

68 A.G.A.S. Sec. IV, Inventarios, Leg. 1422. Inventario parroquial de Bollullos del Condado. Año de 1884. Firman el Cura Arcipreste Antonio Márquez Lobo y el Capellán de Jesús, Antonio P. Jesús. 29 de diciembre de 1884 .

69 A.D.H. Bollullos Par del Condado, Licencia a D. Francisco Delgado y Neble para construir una capilla adosada a la parroquia, 29 de febrero de 1907.

70 A.D.H. Bollullos Par del Condado, Licencia a D. Francisco Delgado y Neble para construir una capilla adosada a la parroquia, 29 de febrero de 1907. 
ubicación del sagrario y una mayor decencia para el altar de culto del Sagrado Corazón de Jesús, cuya Cofradía acababa de adquirir en Madrid una talla de extraordinario mérito ${ }^{71}$.

Salvando la precaución de que ninguno de estos cementerios de Almonte y Bollullos han llegado a nuestros días, bien pudiéramos aventurar que al menos en su distribución y forma parecen coincidir estos cementerios coetáneos. Un espacio cuadrangular, más largo que ancho, cercado, con capilla al fondo frente a la puerta principal. En el caso del cementerio de Bollullos aún queda como testigo el monolito con la cerámica de la Virgen de la Soledad. En el caso del cementerio almonteńo queda el espacio que ocupaba y que se ha reconvertido en parque.

En estos tiempos en que se ha perdido el sentido religioso por un aniquilamientoideológico del cristianismo y de otras religiones; las creencias, ritos funerarios, enterramientos quedarán como reliquias silentes de un culto extinguido. Sic transit gloria mundi.

71 A.D.H. Bollullos Par del Condado, Informe de D. Antonio Márquez Lobo, 2 de marzo de 1908. 